\title{
rRNA Sequences and Evolutionary Relationships among Toxic and Nontoxic Cyanobacteria of the Genus Microcystis
}

\author{
BRETT A. NEILAN, ${ }^{1 *}$ DANIEL JACOBS, ${ }^{1}$ THERESE DEL DOT, ${ }^{2}$ LINDA L. BLACKALL, ${ }^{2}$ \\ PETER R. HAWKINS, ${ }^{3}$ PETER T. COX ${ }^{3}$ AND AMANDA E. GOODMAN ${ }^{4}$ \\ School of Microbiology and Immunology, The University of New South Wales, Sydney, New South Wales 2052, ${ }^{1}$ \\ School of Microbiology, The University of Queensland, Brisbane, Queensland $4072,{ }^{2}$ Australian Water \\ Technologies, West Ryde, New South Wales $2114,{ }^{3}$ and School of Biological Sciences, \\ The Flinders University of South Australia, Adelaide, South Australia 5001, ${ }^{4}$ Australia
}

\begin{abstract}
A primary-structure analysis of the $16 \mathrm{~S}$ rRNA gene was performed with 10 strains representing five described and one unidentified species of the genus Microcystis. The phylogenies determined illustrate the evolutionary affiliations among Microcystis strains, other cyanobacteria, and related plastids and bacteria. A cluster of 10 strains that included hepatotoxic isolates identified as Microcystis aeruginosa formed a monophyletic group. However, the genus Microcystis appeared to be polyphyletic and contained two strains that clustered with unicellular cyanobacteria belonging to the genus Synechococcus. The clustering of related Microcystis strains, including strains involved in the production of the cyclic peptide toxin microcystin, was consistent with cell morphology, gas vacuolation, and the low $\mathrm{G}+\mathrm{C}$ contents of the genomes. The Microcystis lineage was also distinct from the lineage containing the unicellular genus Synechocystis and the filamentous, heterocystforming genus Nostoc. The secondary structure of a Microcystis 16S rRNA molecule was determined, and genus-specific sequence signatures were used to design primers that permitted identification of the potentially toxic cyanobacteria belonging to the genus Microcystis via DNA amplification.
\end{abstract}

The Cyanobacteria is a diverse bacterial phylum with respect to form, function, and habitat. On the basis of microfossil and geochemical evidence the origin of cyanobacterium-like organisms has been dated to the late Precambrian era. On the basis of the results of phylogenetic studies workers have inferred that the cyanobacterial phylum is 1 of the 11 bacterial phyla $(32,42)$. The possibility that eukaryotic chloroplasts arose from a cyanobacterial ancestor by a symbiotic event has also been inferred on the basis of molecular data $(8,38)$.

Members of the genus Microcystis are a major cause of freshwater noxious cyanobacterial blooms, which have a broad geographical distribution. The microcystins, a family of cyclic heptapeptide toxins that are not synthesized ribosomally (3) and are produced by most members of this genus, cause acute hepatotoxicity in agricultural livestock. Recent epidemiological data have also linked chronic subacute consumption of microcystins to human liver tumor promotion (5). The increasing occurrence of Microcystis blooms in major sources of human drinking water makes identification and prediction of these toxic blooms very important.

Due to the variably expressed and minor morphological and developmental characteristics used for identification, classification of cyanobacterial strains at the genus or species level may be ambiguous (29), particularly when laboratory cultures and environmental isolates are compared (7). The current cyanobacterial taxonomy does not provide an unequivocal system for identification of the toxigenic and bloom-forming genus Microcystis (20). Depending on the taxonomic treatises used for classification, which differ in their emphasis on the cell size, shape, buoyancy, and toxicity of the planktonic, freshwater cyanobacteria, different generic assignments may be made. Thus, previously, some Microcystis strains have been placed in the genus Synechocystis $(29,30)$.

The present study was undertaken to create an alternative

* Corresponding author. Phone: 612385 2092. Fax: 6123136528. E-mail: b.neilan@unsw.edu.au. molecular genetics-based taxonomy for the cyanobacterial genus Microcystis. The 16S rRNA genes of 10 Microcystis strains, representing geographically diverse populations, were amplified and then cloned and sequenced or were sequenced directly. A $16 \mathrm{~S}$ rRNA gene-based phylogeny of the isolates which we examined, together with other members of the genus $\mathrm{Mi}$ crocystis (26), was inferred. Specific primers that were based on unique primary and secondary sequence structures and an optimized PCR were developed for rapid identification of potentially toxin-producing Microcystis strains. In this paper we describe genetic diversity among organisms previously identified as members of the genus Microcystis, some of which have ecological and medical importance. A sensitive and specific approach to identification and reclassification of Microcystis strains, which is based on stable genetic characteristics, is proposed.

\section{MATERIALS AND METHODS}

Bacterial strains and toxicity assays. Cyanobacterial strains either were obtained from international culture collections or were supplied by Australian culture collections. The strains (Table 1) whose designations begin with PCC NIES, and AWT were obtained from the Pasteur Culture Collection (Paris, France) (30), the National Institute for Environmental Studies (Tsukuba, Japan) (24), and Australian Water Technologies (Sydney, Australia), respectively. Cultures were maintained in either JM, MA (24), or BG-11 media (6) at $25^{\circ} \mathrm{C}$ with a light intensity of $1,500 \mathrm{~lx}$ until the mid-logarithmic to late logarithmic growth phase. Microcystins were detected by a mouse bioassay, by high-performance liquid chromatography (HPLC), or by a protein phosphatase $2 \mathrm{~A}$ inhibition assay by using standard procedures $(2,9,34)$.

Amplification, cloning, and sequencing. Total genomic DNA was extracted as previously described (25). Alternatively, a PCR template was prepared by rapid cell lysis in the presence of an ion-exchange resin and nonionic detergents (25). 16S rRNA gene PCR amplifications were performed by using primers $27 \mathrm{Fl}$ (UFP) and 1494Rc(URP) (Table 2) together with PCR reagents as previously described (27). Thermal cycling was performed at $94^{\circ} \mathrm{C}$ for $4 \mathrm{~min}$; this was followed by 30 cycles consisting of $94^{\circ} \mathrm{C}$ for $20 \mathrm{~s}, 50^{\circ} \mathrm{C}$ for $30 \mathrm{~s}$, and $72^{\circ} \mathrm{C}$ for $2 \mathrm{~min}$.

A Microcystis-specific PCR was performed as described above for 16S rRNA gene amplification except that primers $209 \mathrm{~F}$ and $409 \mathrm{R}$ in the $5^{\prime}$ region of the $16 \mathrm{~S}$ rRNA gene replaced consensus primers $27 \mathrm{Fl}(\mathrm{UFP})$ and $1494 \mathrm{Rc}$ (URP). Also, a two-step PCR thermal cycling program was used; this program included an initial denaturation step at $95^{\circ} \mathrm{C}$ for $3 \mathrm{~min}$, which was followed by 30 cycles consisting of denaturation at $95^{\circ} \mathrm{C}$ for $10 \mathrm{~s}$ and an annealing-extension step at $70^{\circ} \mathrm{C}$ for 1 min. Taq DNA polymerase was added to the Microcystis-specific reaction components preheated to $95^{\circ} \mathrm{C}$. The conditions used for the control, cyanobacterium- 
TABLE 1. Description of cyanobacterial strains, including strains for which 16S rRNA gene sequence data were generated ${ }^{a}$

\begin{tabular}{|c|c|c|c|c|c|c|}
\hline Strain & Origin & $\begin{array}{l}\text { Cell diam } \\
(\mu \mathrm{m})\end{array}$ & Habit $^{b}$ & $\begin{array}{c}\mathrm{G}+\mathrm{C} \text { content } \\
(\mathrm{mol} \%)\end{array}$ & $\begin{array}{c}\text { Gas } \\
\text { vacuoles }\end{array}$ & $\begin{array}{c}\text { Toxin } \\
\text { production }^{c}\end{array}$ \\
\hline \multicolumn{7}{|l|}{ Genus Microcystis } \\
\hline Microcystis sp. strain AWT139 & Australia & 4 & C & $\mathrm{ND}^{d}$ & + & + \\
\hline M. aeruginosa NIES89 & Japan & 4 & C & ND & + & + \\
\hline M. aeruginosa NIES98 & Japan & $3-4$ & $\mathrm{C}$ & ND & + & - \\
\hline M. aeruginosa PCC7005 & United States & 4 & $\mathrm{U}$ & 45.4 & - & + \\
\hline M. aeruginosa PCC7806 & The Netherlands & $3-3.5$ & $\mathrm{U}$ & 41.6 & + & + \\
\hline M. aeruginosa PCC7820 & Scotland & $3-3.5$ & $\mathrm{U}$ & 42.1 & + & + \\
\hline M. aeruginosa PCC7941 & Canada & 4 & $\mathrm{U}$ & 42.5 & + & + \\
\hline M. elabens NIES42 & Japan & 2 & $\mathrm{U}$ & ND & + & - \\
\hline M. holsatica NIES43 & Japan & 2 & $\mathrm{U}$ & ND & + & - \\
\hline M. viridis NIES102 & Japan & 4 & $\mathrm{U}$ & ND & + & + \\
\hline M. wesenbergii NIES107 & Japan & $4-5$ & $\mathrm{C}$ & ND & + & + \\
\hline M. wesenbergii NIES112 & Japan & $5-6$ & $\mathrm{C}$ & ND & + & - \\
\hline Synechocystis sp. strain PCC6803 & United States & $2-3$ & $\mathrm{U}$ & 47.4 & - & ND \\
\hline Synechococcus sp. strain PCC6301 & United States & $1-1.2$ & $\mathrm{U}$ & 55.1 & - & ND \\
\hline
\end{tabular}

${ }^{\alpha}$ The unicellular cyanobacteria used in this study were coccoid, were isolated from freshwater sources, and lacked phycoerythrin $(24,30,39)$. 16S rDNA sequences for all of the Microcystis strains except M. aenuginosa PCC7806 and NIES89 (26) were generated in the present study.

${ }^{b} \mathrm{C}$, colonial; $\mathrm{U}$, unicellular.

Microcystin production was determined by a mouse bioassay, HPLC, and/or a protein phosphatase $2 \mathrm{~A}$ inhibition assay (data not shown).

${ }^{d} \mathrm{ND}$, not determined.

specific PCR were identical to those used for the Microcystis-specific PCR except that a lower annealing-extension temperature $\left(65^{\circ} \mathrm{C}\right)$ was used.

PCR products were cloned by using the TA Cloning system vector, pCR II (Invitrogen, San Diego, Calif.). Manual sequencing was performed with either a Cyclist exo ${ }^{-}$Pfu kit (Stratagene, La Jolla, Calif.) or an fmol cycle sequencing kit (Promega, Madison, Wis.). Automated DNA sequencing was performed with a PRISM cycle sequencing system and a model 373 sequencer (Applied Biosystems, Inc., Foster City, Calif.). Oligonucleotide primers were synthesized with a model Oligo 1000 DNA synthesis system (Beckman, Fullerton, Calif.) and were purified by reverse-phase chromatography.

Phylogenetic analyses. DNA sequences were aligned by using the programs Pileup and GCG (13) and the multiple-sequence alignment tool from Clustal W (36). The sequence alignment was confirmed manually and was checked by using both primary- and secondary-structure considerations for the 16S rRNA molecule. The aligned sequences were studied by using genetic distance and maximumparsimony methods for phylogenetic inference. Ambiguous characteristics (where a deletion, insertion, or unidentified state was recorded for any strain) were removed from the alignment data. For all multiple-sequence alignments and phylogenetic inference programs the input order of taxa was randomized. Genetic distances $(D)$ were calculated by using the formula of Jukes and Cantor, where $D=-3 / 4 \ln (1-4 / 3 d)$ and $d$ is the level of sequence dissimilarity (18). The phylogenetic inference protocols DNADIST, NEIGHBOR, DNAPARS, CON SENSE, and SEQBOOT were supplied by the PHYLIP package (version $3.57 \mathrm{c}$ ) (11). All sequence manipulation and phylogeny programs were made available by the Australian National Genome Information Service (Sydney, Australia).

Nucleotide sequence accession numbers. The 16S rDNA sequences of Microcystis sp. strain AWT139, $M$. viridis NIES102, $M$. wesenbergii NIES107 and NIES112, $M$. elabens NIES42, $M$. holsatica NIES43, and $M$. aeruginosa NIES98 PCC7005, PCC7820, and PCC7941 have been deposited in the GenBank database under accession no. MAU40331, MVU40332, MWU40333, MWU40334, MEU40335, MHU40336, MAU40337, MAU40338, MAU40339, and MAU40340, respectively.

\section{RESULTS}

Synthetic oligonucleotide primers were designed and used for $16 \mathrm{~S}$ rRNA gene amplification and sequencing. Because of the low levels of homology to cyanobacterial sequences, it was

TABLE 2. Cyanobacterial $16 \mathrm{~S}$ rRNA gene amplification and sequencing primers

\begin{tabular}{|c|c|c|c|c|}
\hline Primer & Sequence $^{a}$ & Locus $^{b}$ & $T_{\mathrm{m}}\left({ }^{\circ} \mathrm{C}\right)^{c}$ & Application $^{d}$ \\
\hline $27 \mathrm{Fl}$ & AGAGTTTGATCCTGGCTCAG & $8-27$ & 56 & $\mathrm{~S}$ \\
\hline 27Fl(UFP) & TAGTGTAAAACGACGGCCAGTAGAGTTTGATCCTGGCTCAG & $8-27$ & 56 & A \\
\hline $209 \mathrm{~F}$ & ATGTGCCGCGAGGTGAAACCTAAT & 179-209 & 68 & A \\
\hline $341 \mathrm{R}$ & CTGCTGCCTCCCGTAGG & $341-356$ & 54 & $\mathrm{~S}$ \\
\hline $356 \mathrm{~F}$ & CTCCTACGGGAGGCAGCAG & $338-356$ & 60 & $\mathrm{~S}$ \\
\hline 409R & TTACAA(C/T)CCAA(G/A) (G/A) (G/A)CCTTCCTCCC & $409-431$ & 68 & A \\
\hline $519 \mathrm{R}$ & GTATTACCGCGGCTGCTG & $519-536$ & 54 & $\mathrm{~S}$ \\
\hline $530 \mathrm{~F}$ & GTGCCAGCAGCCGCGG & $515-530$ & 54 & $\mathrm{~S}$ \\
\hline $929 \mathrm{R}$ & TCC(T/A)CCGCTTGTGCGGGG & $929-945$ & 54 & $\mathrm{~S}$ \\
\hline $942 \mathrm{~F}$ & GGGCCCGCACAAGCGG & $927-942$ & 54 & $\mathrm{~S}$ \\
\hline $1114 \mathrm{~F}$ & GCAACGAGCGCAACCC & $1099-1114$ & 50 & S \\
\hline $1221 \mathrm{R}$ & ATTGTAG(T/C)ACGTGTGTAGCC & $1221-1240$ & 55 & $\mathrm{~S}$ \\
\hline $1241 \mathrm{~F}$ & GCTACACACGT(A/G)CTACAATG & $1222-1241$ & 55 & $\mathrm{~S}$ \\
\hline $1385 \mathrm{R}$ & GCGGTGTGTACAAGGCCC & $1385-1402$ & 56 & $\mathrm{~S}$ \\
\hline 1494Rc & TACGGCTACCTTGTTACGAC & $1494-1513$ & 56 & $\mathrm{~S}$ \\
\hline 1494Rc(URP) & TAGCAGGAAACAGCTATGACCTACGGCTACCTTGTTACGAC & $1494-1513$ & 56 & A \\
\hline
\end{tabular}

${ }^{a}$ Oligonucleotide sequences are given in $5^{\prime}$-to- $3^{\prime}$ orientation. The underlined sequences are the sequences of the linked universal sequencing primers which were attached to assist in successive sequencing of cloned PCR products.

${ }^{b}$ Position of primer based on E. coli $16 \mathrm{~S}$ rRNA numbering.

c Theoretical temperature for primer-template disassociation.

${ }^{d} \mathrm{~S}$, DNA sequencing primer; A, DNA amplification primer. 
necessary to refine the previously described Escherichia colibased and bacterial consensus 16S ribosomal DNA (rDNA) primers $(22,40)$ for our sequencing study. A set consisting of 12 primers enabled us to sequence both strands of the $16 \mathrm{~S}$ rRNA gene with contiguous overlaps. Both strands of the gene were sequenced in duplicate. The $16 \mathrm{~S}$ rRNA gene PCR products of four Microcystis strains, Microcystis aeruginosa PCC7806 and NIES89, Microcystis wesenbergii NIES107, and Microcystis elabens NIES42, were cloned. Four separate clones of each of these strains were isolated and sequenced to ensure that no amplification errors occurred. Only 1 of the 16 clones sequenced exhibited apparent Taq polymerase-directed mutations, and no chimeric PCR molecules were observed.

Complete sequences for both strands of the $16 \mathrm{~S}$ rDNA were generated for the region from position 27 to position 1494 ( $E$. coli numbering) for 10 Microcystis strains representing $M$. aeruginosa, $M$. elabens, Microcystis holsatica, Microcystis viridis, and $M$. wesenbergii. The assembled sequences were analyzed by using the BLAST program (1) for alignment with database sequences and to ensure that the sequences generated were cyanobacterial in origin. The $16 \mathrm{~S}$ rRNA gene sequences determined were compared to each other and to previously published almost complete 16S rRNA gene sequences for cyanobacteria and related organisms.

We aligned the 16S rRNA gene primary structures of the Microcystis strains described above, $M$. aeruginosa PCC7806 and NIES89 (26), the unicellular cyanobacterium Synechococcus sp. strain PCC6301 (37), Synechocystis sp. strain PCC6803 (19), a cyanelle (Cyanophora paradoxa) (14), a plastid (Euglena gracilis chloroplast) (15), a prochlorophyte (Prochloron sp.) (38), a filamentous, heterocyst-forming cyanobacterium (Nostoc muscorum PCC7120) (23), and the outgroup organism $\mathrm{Ba}$ cillus subtilis 168 (a gram-positive bacterium) (35). These aligned sequences formed the basis for successive phylogenetic inferences. The derived sequences, including both conserved and variable domains of the $16 \mathrm{~S}$ rRNA primary structure, were used to measure genetic divergence within the genus Microcystis. After ambiguous characteristics were removed from the alignment, 1,346 nucleotide positions were used for successive phylogenetic analyses. Several trees were reconstructed by using different methods of analysis, such as maximum parsimony and genetic distance metrics. The input order of sequences into the phylogeny programs and the selection of outgroups used were also varied during this study.

The tree topology shown in Fig. 1 was indicative of other statistical representations, including parsimony and consensus trees, based on the sequence data obtained. M. elabens NIES42 and $M$. holsatica NIES43 exhibited, on average, only 85 and $87 \%$ sequence similarity, respectively, to the other Microcystis strains. The level of sequence similarity to Synechococcus sp. strain PCC6301 was, however, significantly higher (91\%). The relationship of $M$. elabens and $M$. holsatica to the genus Synechococcus, instead of other members of the genus Microcystis, was illustrated by the evolutionary distances and relative clustering shown in Fig. 1. The remaining Microcystis strains clustered phylogenetically and exhibited levels of sequence similarity ranging from 91 to $99 \%$. Four strains of this cluster, $M$. aeruginosa NIES89, PCC7806, and PCC7005 and $M$. wesenbergii NIES112, were isolated from geographically distinct regions (Table 1) but exhibited 99\% 16S rRNA gene sequence similarity. The proposed type strain of the type species of the genus Microcystis, M. aeruginosa PCC7941 (30), which was isolated in Canada, exhibited levels of sequence similarity of 96 to $98 \%$ with the other strains belonging to this cluster. $M$. aeruginosa PCC7820 exhibited an average level of similarity of only $95 \%$ to all of the other Microcystis strains studied except those

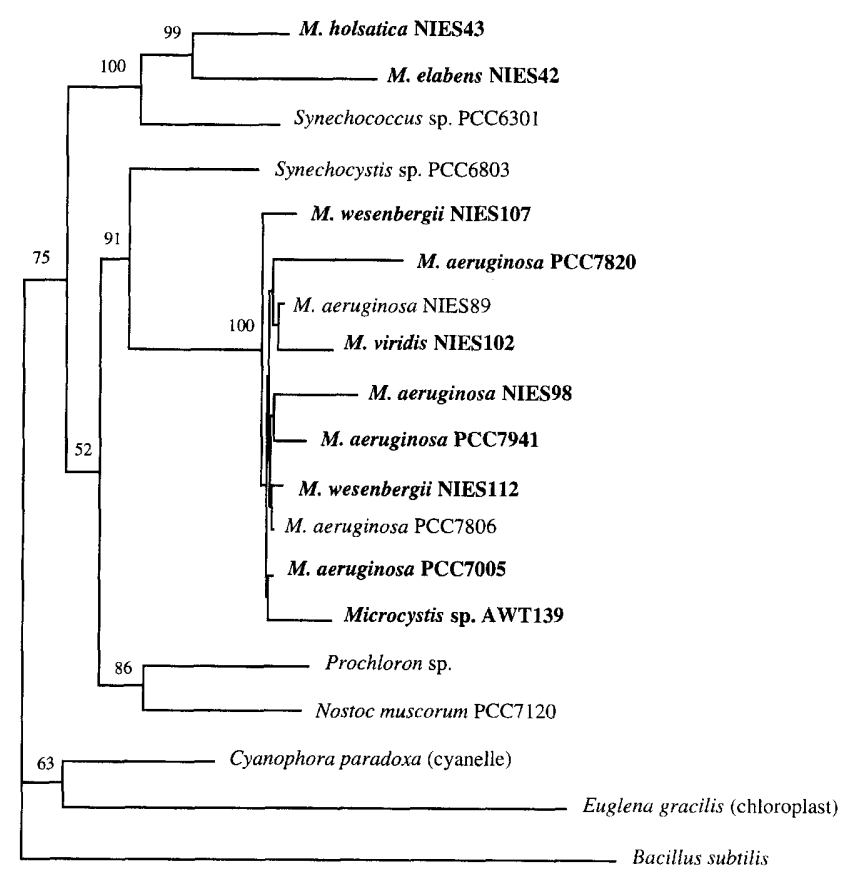

0.05

FIG. 1. Phylogenetic affiliations of the strains belonging to the genus Microcystis, other cyanobacteria, and related microorganisms derived from almost complete 16S rRNA gene sequences. An alignment of 1,346 unambiguous nucleotides was used to calculate genetic distances by the method of Jukes and Cantor (18). The phenogram was reconstructed from a pairwise distance matrix by using the neighbor-joining method of Saitou and Nei (31). Scale bar $=5$ base substitutions per 100 nucleotide positions. Organisms in boldface type were sequenced during this study, and the accession numbers are given in the text. Bootstrap values (for branches present in more than $50 \%$ of 100 resamplings of the data) are indicated at nodes (10).

belonging to the Synechococcus cluster (Fig. 1). The strains identified as $M$. viridis NIES102 and $M$. wesenbergii NIES107 were located on the same terminal branch after a cladistic analysis of the sequence data was performed (data not shown) and were equally divergent from the cluster containing the remaining Microcystis strains (Fig. 1), with average levels of similarity of 97 and $96 \%$, respectively. When the strains of $M$. elabens and $M$. holsatica that clustered with Synechococcus sp. strain PCC6301 were not included, (Fig. 1), the evolutionary distances among strains assigned to $M$. aeruginosa were greater than the evolutionary distances observed at the interspecies level (Fig. 1). The average level of sequence similarity between Synechocystis sp. strain PCC6803 and all of the strains belonging to the major Microcystis cluster was $85 \%$.

Specific primers were designed and were based on the $16 \mathrm{~S}$ rRNA gene sequences generated (Table 2). One of the PCR primers, primer $209 \mathrm{~F}$ (forward), was located at positions 179 to 209 of the gene (E. coli numbering; positions 162 to 185 based on the $M$. aeruginosa PCC7806 sequence). When an optimized PCR was performed with this primer in combination with downstream primer 409R (reverse) (Table 2), the DNAs of all of the strains belonging to the major Microcystis cluster were selectively amplified (Fig. 2). The results of 50\% lethal dose determinations in a mouse bioassay system and postmortem histology revealed that $M$. aeruginosa PCC7806, PCC7941, AWT139, NIES89, and PCC7820, $M$. viridis NIES102, and $M$. wesenbergii NIES107 were hepatotoxin producers $(9,30$; data not shown). HPLC and capillary electrophoresis revealed that 


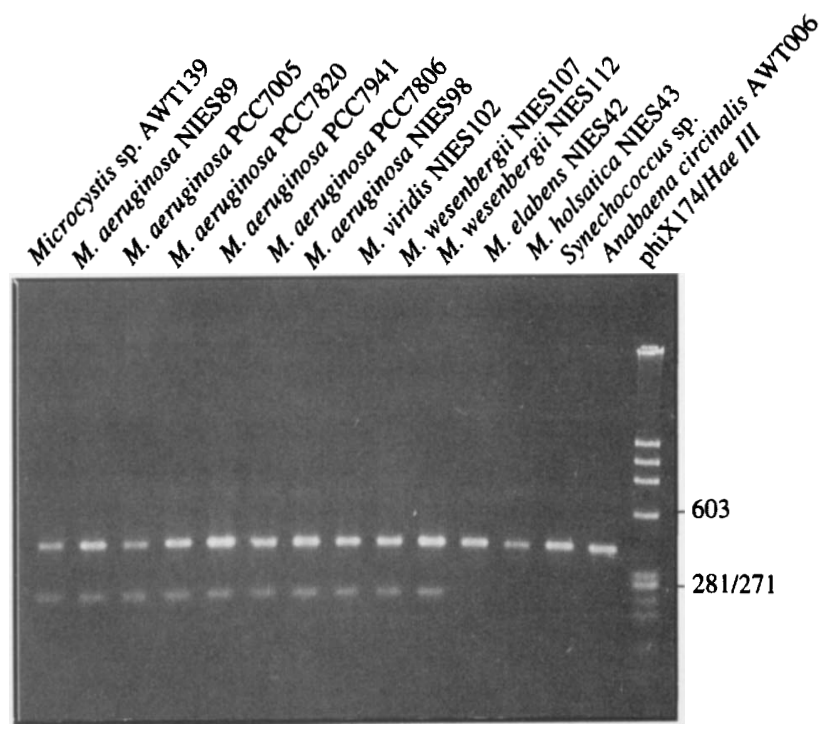

FIG. 2. Analysis of PCR products from the cyanobacterial 16S rRNA gene related to genus-specific sequence signatures. Control bands $(\sim 400 \mathrm{bp})$ were generated by using bacterial and cyanobacterial consensus primers 27Fl(UFP) and 409R, while primers $209 \mathrm{f}$ and 409R, which are specific for strains of the genus Microcystis, were used to amplify the smaller ( $\sim 200-b p)$, specific band (Table 2). The DNA amplification conditions were the same as those described previously (28), except that the cycle annealing temperature was $65^{\circ} \mathrm{C}$ (cyanobacterial PCR) or $70^{\circ} \mathrm{C}$ (Microcystis PCR) and Taq polymerase was added to the remaining reaction components, which were preheated to $95^{\circ} \mathrm{C}$. The strains belonging to the major Microcystis cluster (Fig. 1) produced both Microcystisspecific and cyanobacterial control bands. DNAs from other strains of cyanobacteria, including $M$. elabens NIES42, $M$. holsatica NIES43, Synechococcus sp. strain AWT400, and A. circinalis AWT006, were not amplified in this genusspecific PCR. Electrophoresis was on a $2 \%$ agarose-TAE gel that was stained with ethidium bromide (17).

the hepatotoxins were isoforms of microcystin (6a). M. aeruginosa PCC7005, as determined by the mouse bioassay and as previously reported (9), was nontoxic. However, the more sensitive protein phosphatase inhibition assay showed that this strain is a low-level microcystin producer (2). Based on the observed variable expression of toxin in cultured Microcystis strains $(7,34)$ and the different levels of sensitivity of available toxin assays, no correlation between $16 \mathrm{~S}$ rRNA gene evolution and strain toxicity was observed. However, the major Microcystis cluster exhibited a high incidence of toxic representatives and was delineated from nontoxic taxonomic groups (Fig. 1). Differences in the primary and secondary structures of the gene between potentially toxin-producing Microcystis species and other cyanobacteria provided sequence signatures useful for rapid identification of members of this genus. DNAs from several strains of cyanobacteria, including $M$. elabens NIES42, $M$. holsatica NIES43, Synechococcus sp. strain AWT400, and Anabaena circinalis AWT006, were not amplified when the Microcystis-specific PCR was performed (Fig. 2). Other representative strains belonging to the genera Anabaena, Cylindrospermopsis, Lyngbya, Nodularia, Nostoc, and Pseudanabaena were also not suitable as templates for the Microcystis-specific PCR (data not shown). A control, cyanobacterium specific PCR, in which we used the primers shown in Table 2 at positions 27 (forward) and 409 (reverse), was performed to determine efficacy of PCR templates (Fig. 2).

\section{DISCUSSION}

Certain members of the genus Microcystis and $M$. aeruginosa PCC7005 in particular have been included by some authors in the loose assemblage designated the Synechocystis group (29, 39). The phylogeny in Fig. 1 reveals that there is a definite delineation between the major Microcystis cluster and a representative of the high-G+C-content cluster of the genus Synechococcus (19). M. aeruginosa PCC7005, which previously was included in the genus Synechocystis (29) and lacks gas vesicles, branched deeply within the major Microcystis cluster, which is consistent with its current classification $(30,39)$. The high levels of sequence similarity between geographically diverse strains of $M$. aeruginosa and their relatives support the cosmopolitan nature of this genus. We calculated insignificant evolutionary distances between strains of $M$. aeruginosa from land-locked freshwater bodies in Australia, North America, Europe, and Asia.

Minor and variable morphometric parameters may have led to the identification of $M$. wesenbergi and $M$. viridis, whose separation from $M$. aeruginosa is difficult to justify based on the results of $16 \mathrm{~S}$ rRNA gene analyses. $M$. elabens and $M$. holsatica are nontoxic (data not shown) and have considerably smaller cell diameters than the other Microcystis strains included in this study (Table 1). Based on the available 16S rDNA sequence information, these organisms have been included in the Synechococcus cluster (Fig. 1). Additional sequence information for the botanically described unicellular genera Aphanocapsa and Aphanothece may result in a more appropriate generic nomenclature for these Microcystis strains of the Synechococcus cluster $(21,29)$. The clustering of $M$. elabens NIES42 and $M$. holsatica NIES43 with the genus Synechococcus has been supported by the genetic relatedness within the cyanobacteria based on sequence heterogeneity of the phycocyanin operon and the 16S-23S rRNA internally transcribed spacer $(27,28)$. The phycocyanin gene data also support the apparently random branching of species within the major cyanobacterial cluster (Fig. 1) (28). 16S rDNA sequence data readily supported the close relationship of the remaining Microcystis strains. The classification of $M$. wesenbergii NIES112 as a species distinct from $M$. aeruginosa was not supported, whereas both $M$. viridis NIES102 and $M$. wesenbergii NIES107 may deserve independent status. However, the observed genetic distances between strains assigned to $M$. aeruginosa could also encompass all of the strains described in the major Microcystis cluster (Fig. 1), which exhibited a maximum level of sequence difference of $9 \%$. Therefore, the genus Microcystis or M. aeruginosa may be described within these molecular taxonomic limits. DNA-DNA hybridization studies may reveal actual valid species limits within the genus Microcystis.

The genetic relationships among the genera Synechocystis, Synechococcus, and Prochlorophytes and the cyanobacterial cluster, as indicated by the phenogram topology in Fig. 1, were identical to the relationship described previously $(14,41)$. It has been difficult to determine an accurate time scale for the evolution of cyanobacterial groups, although microfossil records tentatively indicate that ancient and morphologically diverse members of this phylum appeared more than several billion years ago (33). The complete 16S rRNA gene sequences described in this paper revealed a high level of conservation and a relatively late onset of divergence in the Microcystis cluster. This pattern of evolution is also reflected by the cyanobacterial radiation as a whole $(14,41)$. It appears that the morphological, functional, and geographical adaptation of cyanobacteria is not mirrored by the molecular evolution of these organisms.

It has been shown that sequence signatures found in the $16 \mathrm{~S}$ rRNA gene locus are suitable for differentiation of bacteria at inter- and intrageneric taxonomic levels $(12,42)$. The Microcystis-specific PCR described above allowed us to selectively amplify the 16S rRNA genes of potentially microcystin-producing Microcystis strains (Fig. 2). Differentiation of Microcys- 
tis strains based on a mismatch between PCR primers and template DNA was supported by phylogenetic relationships (Fig. 1). Variable culture conditions did not affect the detection of Microcystis strains based on 16S rRNA gene sequence diversity. It should be noted that several other cyanobacterial enera produce the hepatoxic heptapeptide microcystin $(3,16,34)$ and that DNAs of representatives of these groups were not amplified by using the specific PCR described here. Significant polymorphisms, including extensive deleted regions, in the calculated secondary structure of the $16 \mathrm{~S}$ rRNA molecule of $M$. aeruginosa PCC7806 compared to the 16S rRNA molecules of other bacteria were observed at positions 203, 449, and 830 (data not shown).

In an attempt to adequately replace systematic analyses based on observed phenotypes, we began a study of evolutionarily conserved genes, including the genes that encode smalland large-subunit rRNAs, RNA polymerase, and elongation factors, in potentially bloom-forming and toxic cyanobacteria. The results presented here include an alternative reliable taxonomy, as well as an inferred phylogeny, based on 16S rRNA gene nucleotide sequence profiles. Genotypic relationships between members of the genus Microcystis should contribute to rapid and accurate identification of cyanobacterial strains present in the complex natural populations of potentially toxic cyanobacterial blooms.

\section{ACKNOWLEDGMENTS}

The secondary-structure analysis was generously performed by Robin Gutell (University of Colorado). The automated sequence analysis was performed by Jenny Cassady (University of Queensland) and Cameron McCrae (Australian National University). Bronwyn Robertson (University of New South Wales) kindly assisted with the phylogenetic analyses. Chemical data for cyanobacterial toxicity were provided by Nimal Chandrasena (Australian Water Technologies).

This research was supported by the Australian Research Council, by Australian Water Technologies, and by the Commonwealth Scientific and Industrial Research Organisation (Division of Fisheries).

\section{REFERENCES}

1. Altschul, S. F., W. Gish, W. Miller, E. W. Myers, and D. J. Lipman. 1990. Basic local alignment search tool. J. Mol. Biol. 215:403-410.

2. An, J., and W. W. Carmichael. 1994. Use of a colorimetric protein phosphatase inhibition assay and enzyme linked immunosorbent assay for the study of microcystins and nodularins. Toxicon 32:1495-1507.

3. Arment, A. R., and W. W. Carmichael. 1995. Evidence that microcystin is a thio-template product. J. Phycol. 32:591-597.

4. Brosius, J., T. J. Dull, D. Sleeter, and H. F. Noller. 1981. Gene organisation and primary structure of a ribosomal RNA operon from Escherichia coli. J. Mol. Biol. 148:107-127.

5. Carmichael, W. W. 1992. Cyanobacteria secondary metabolites-the cyanotoxins. J. Appl. Bacteriol. 72:445-459.

6. Castenholz, R. W., and J. B. Waterbury. 1989. Section 19. Oxygenic photosynthetic bacteria, group 1, cyanobacteria, p. 1710-1728. In J. T. Staley, M. P. Bryant, N. Pfennig, and J. G. Holt (ed.), Bergey's manual of systematic bacteriology, vol. 3. Williams and Wilkins Co., Baltimore, Md.

6a.Chandrasena, N. Personal communication.

7. Doers, M. P., and D. L. Parker. 1988. Properties of Microcystis aeruginosa and $M$. flos-aquae (Cyanophyta) in culture: taxonomic implications. J. Phycol. 24:502-508

8. Douglas, S. E., and S. Turner. 1991. Molecular evidence for the origin of plastids from a cyanobacterium-like ancestor. J. Mol. Evol. 33:267-273.

9. Eloff, J. N. 1981. Autecological studies on Microcystis, p. 71-96. In W. W. Carmichael (ed.), The water environment-algal toxins and health. Plenum Press, New York, N.Y.

10. Felsenstein, J. 1985. Confidence limits on phylogenies: an approach using the bootstrap. Evolution 39:166-170.

11. Felsenstein, J. 1989. PHYLIP. Phylogeny inference package. Cladistics 5:164-166.

12. Fox, G. E., J. D. Wisotzkey, and P. Jurtshuk, Jr. 1992. How close is close: 16S rRNA sequence identity may not be sufficient to guarantee species identity. Int. J. Syst. Bacteriol. 39:166-170.

13. Genetics Computer Group. 1994. Wisconsin package, version 8, program manual. Genetics Computer Group, Madison, Wis.

14. Giovanonni, S. J., S. Turner, G. J. Olsen, S. Barns, D. J. Lane, and N. R.
Pace. 1988. Evolutionary relationships among cyanobacteria and green chloroplasts. J. Bacteriol. 170:3584-3592.

15. Graf, L., E. Roux, E. Stutz, and H. Kessel. 1982. Nucleotide sequences of a Euglena gracilis chloroplast gene coding for the 16S rRNA: homologies to $E$. coli and Zea mays chloroplast 16S rRNA. Nucleic Acids Res. 10:6369-6381.

16. Honkanen, R. E., F. R. Caplan, K. K. Baker, C. L. Baldwin, S. C. Bobzin C. M. Bolis, G. M. Cabrera. L. A. Johnson, J. H. Hung, L. K. Larsen, I. A Levine, R. E. Moore, C. S. Nelson, G. M. L. Patterson, K. D. Tschappat, G. D. Tuang, A. L. Boynton, A. R. Arment, J. An, W. W. Carmichael, K. D. Rodland, B. E. Magun, and R. A. Lewin. 1995. Protein phosphatase inhibitory activity in extracts of cultured blue-green algae (Cyanophyta). J. Phycol. 31: $478-486$.

17. Jacobs, D., and B. A. Neilan. 1995. Long term preservation of DNA in agarose gels using 70\% ethanol. BioTechniques 19:892-894.

18. Jukes, T. H., and C. R. Cantor. 1969. Evolution of protein molecules, p. 21-132. In H. N. Munro (ed.), Mammalian protein metabolism, vol. 3. Academic Press, Inc., New York, N.Y.

19. Kaneko, T., A. Tanaka, S. Sato, H. Kotani, T. Sazuka, N. Miyajima, M. Sugiura, and S. Tabata. 1995. Sequence analysis of the genome of the unicellular cyanobacterium Synechocystis sp. PCC6803. I. Sequence features in the $1 \mathrm{Mb}$ region from map position $64 \%$ to $92 \%$ of the genome. DNA Res. 2:153-166.

20. Komarek, J. 1991. A review of water-bloom forming Microcystis species, with regard to populations from Japan. Arch. Hydrobiol. Suppl. 64:115-127.

21. Komarek, J., and K. Anagnostidis. 1986. Modern approach to the classification system of cyanophytes. 2. Chroococcales. Arch. Hydrobiol. Suppl. 43:157-226.

22. Lane, D. J., B. Pace, G. J. Olsen, D. A. Stahl, M. L. Sogin, and N. R. Pace. 1985. Rapid determination of $16 \mathrm{~S}$ ribosomal RNA sequences for phylogenetic analyses. Proc. Natl. Acad. Sci. USA 82:6955-6959.

23. Ligon, P. J., K. G. Meyer, J. A. Martin, and S. E. Curtis. 1991. Nucleotide sequence of a 16S rRNA from Anabaena sp. strain PCC 7120. Nucleic Acids Res. 19:4553.

24. National Institute for Environmental Studies. 1991. Microbial Culture Collection list of strains, 3rd ed. Environmental Agency, Tsukuba, Japan.

25. Neilan, B. A. 1995. Identification and phylogenetic analysis of toxigenic cyanobacteria using a multiplex RAPD PCR. Appl. Environ. Microbiol. 61:2286-2291.

26. Neilan, B. A., P. T. Cox, P. R. Hawkins, and A. E. Goodman. 1994. 16S ribosomal RNA gene sequence and phylogeny of toxic Microcystis spp. (cyanobacteria). DNA Sequence 4:333-337.

27. Neilan, B. A., A. E. Goodman, P. T. Cox, and P. R. Hawkins. 1997. Unpublished data.

28. Neilan, B. A., D. Jacobs, and A. E. Goodman. 1995. Genetic diversity and phylogeny of toxic cyanobacteria determined by DNA polymorphisms within the phycocyanin locus. Appl. Environ. Microbiol. 61:3875-3883.

29. Rippka, R. 1988. Recognition and identification of cyanobacteria. Methods Enzymol. 167:28-67.

30. Rippka, R., and M. Herdman. 1992. Pasteur Culture Collection (PCC) of Cyanobacterial Strains in Axenic Culture, vol. 1. Catalogue of strains. Institut Pasteur, Paris, France.

31. Saitou, N., and M. Nei. 1987. The neighbor-joining method: a new method for reconstructing phylogenetic trees. Mol. Biol. Evol. 4:406-425.

32. Schleifer, K. H., and W. Ludwig. 1989. Phylogenetic relationships among bacteria, p. 103-117. In B. Fernholm, K. Bremmer, and Joernvall (ed.), The hierarchy of life. Elsevier Science Publishers, Amsterdam, The Netherlands.

33. Schopf, I. W., and B. M. Packer. 1987. Early archaen (3.3 billion- to 3.5 billionyears old) microfossils from the Warranoona Group, Australia. Science 237: $70-73$.

34. Sivonen, K. 1990. Effects of light, temperature, nitrate, orthophosphate, and bacteria on growth of and hepatotoxin production by Oscillatoria agardhii strains. Appl. Environ. Microbiol. 56:2658-2666.

35. Stewart, G. C., and K. Bott. 1983. DNA sequence of the tandem ribosomal RNA promoter for Bacillus subtilis strain 168. Nucleic Acids Res. 11:6289-6300.

36. Thompson, J. D., D. G. Higgins, and T. J. Gibson. 1994. CLUSTAL W: improving the sensitivity of progressive multiple sequence alignment through sequence weighting, position specific gap penalties and weight matrix choice. Nucleic Acids Res. 22:4673-4680.

37. Tomioka, N., and M. Sugiura. 1983. The complete nucleotide sequence of a $16 \mathrm{~S}$ ribosomal RNA gene from a blue-green alga, Anacystis nidulans. Mol. Gen. Genet. 191:46-50.

38. Urbach, E., D. L. Robertson, and S. W. Chisholm. 1992. Multiple evolutionary origins of prochlorophytes within the cyanobacterial radiation. Nature 335:267-269.

39. Waterbury, J. B., and R. Rippka. 1989. Order Chroococcales (subsection I), p. 1728-1746. In J. T. Staley, M. P. Bryant, N. Pfennig, and J. G. Holt (ed.), Bergey's manual of systematic bacteriology, vol. 3. Williams and Wilkins Co., Baltimore, Md.

40. Weisburg, W. G., S. M. Barns, D. A. Pelletier, and D. J. Lane. 1991. 16S ribosomal DNA amplification for phylogenetic study. J. Bacteriol. 173:697-703.

41. Wilmotte, A. 1994. Molecular evolution and taxonomy of the cyanobacteria, p. 1-25. In D. A. Bryant (ed.), The molecular biology of cyanobacteria. Kluwer Academic Publishers, Dordrecht, The Netherlands.

42. Woese, C. R. 1987. Bacterial evolution. Microbiol. Rev. 51:221-271. 